\title{
ALGUNAS CONSIDERACIONES SOBRE EL MARCO JURÍDICO DE PROTECCIÓN DEL INVERSOR EN DERECHO ESPAÑOL
}

Prof. Dra. MARÍA VALMAÑA OCHAÍTA*

Fecha de entrega: 2 de marzo de 2009.

Fecha de aprobación: 30 de abril de 2009.

RESUMEN: La protección del inversor y la eficiencia de los mercados de valores son dos principios de política legislativa básicos dentro del Derecho del Mercado de Valores, tal y como se refleja en el artículo 13 de la Ley del Mercado de Valores de 1988. El legislador español, como en otros ordenamientos jurídicos de nuestro entorno, ha considerado que la protección del inversor está conectada en gran medida con la información. Por ello ha instaurado un sistema basado en la información conocido como «transparencia informativa o full disclosure» que encuentra sus orígenes en el Derecho anglosajón y se fundamenta en la imposición de un sistema de carga informativa al emisor de valores acompañado de un sistema de supervisión de dicha información, que en España se lleva a cabo por la CNMV. Con ello se pretende garantizar la seguridad y confianza de los inversores a través del acceso de los mismos a una información homogénea, pública y obligatoria para los emisores y, en consecuencia, favorecer la eficiencia de los mercados. Para determinar el grado de protección que el ordenamiento jurídico debe conceder a cada inversor es necesario tener en cuenta las distintas modalidades de inversor que existen en Derecho español y que han sido elevadas a categorías legales. Asimismo, resulta conveniente a la hora de valorar la eficiencia del sistema de protección del inversor conocer si a los mecanismos informativos del sistema le acompañan otros de naturaleza sancionadora e

\footnotetext{
* Resultado de investigación presentada en el Seminario Permanente de Ciencias Sociales el día 18 de febrero de 2009. Maria.Valmana@uclm.es profesora Universidad de Castilla la Mancha. Facultad de Ciencias Sociales España.
} 
indemnizatoria como sucede en países de nuestro entorno a efectos de potenciar el cumplimiento de las normas sobre información.

ABSTRACT: Investor protection and securities market efficiency are two of the main principles of our Securities Law as reflected in article 13 of the Spanish Securities Act. Spanish law-makers, as in other countries, think that investor protection is strongly connected to information. This is why a system based on information called "full disclosure system" has been applied. It comes from American and English law and it is based on mandatory disclosure and an independent agency that controls the accuracy of the information (in Spain, CNMV). This public, mandatory and standard information is the way to guarantee the trust of investors in the markets and in consequence their efficiency. What the level of legal protection for investors should be is a question that can only be answered by looking at the different legal categories of investors. Finally, to make a fair value of the Spanish legal system of investor protection not only the mandatory information should be taken into account, but also coactive mechanisms, like civil liability. These mechanisms make the legal system more efficient.

PALABRAS CLAVE: Transparencia informativa, principio de protección del inversor, eficiencia de los mercados, CNMV, responsabilidad civil, inversor medio, inversor cualificado.

KEYWORDS: Full disclosure, investor protection principle, market efficiency, Spanish securities exchange commission, liability, average investor, accredited investor. 


\section{ALGUNAS CONSIDERACIONES SOBRE EL MARCO JURÍDICO DE PROTECCIÓN DEL INVERSOR EN DERECHO ESPAÑOL}

\section{ASPECTOS DE POLÍtICA-LEgISLATIVA EN RELACIÓN A LA}

\section{PROTECCIÓN DEL INVERSOR EN DERECHO ESPAÑOL}

El artículo 13 de la Ley del Mercado de Valores menciona como funciones de la Comisión Nacional del Mercado de Valores «velar por la transparencia de los mercados de valores, la correcta formación de los precios en los mismos y la protección de los inversores, promoviendo la difusión de cuanta información sea necesaria para la consecución de estos fines».

Se trata, sin duda, de un importante precepto por cuanto recoge algunos de los principios de política legislativa más importantes que informan y subyacen a las normas del denominado Derecho del mercado de Valores como, entre otros, el principio de protección del inversor, el de eficiencia de los mercados (correcta formación de los precios) y el de transparencia informativa. Por otro lado, el artículo 13 LMV considera la transparencia informativa como un instrumento esencial para la consecución de los fines del legislador porque es a través de la misma como se asientan las bases fundamentales de un marco jurídico que garantice la protección del inversor y favorezca la eficiencia de los mercados ${ }^{1}$.

Si bien es evidente la vinculación entre información y protección del inversor y de los mercados, la doctrina se ha planteado cuál es la prioridad de los fines de política legislativa, es decir, si la finalidad primordial de las normas que establecen deberes de información para los emisores es la de proteger al inversor o, por el contrario, la de proteger a los mercados de valores. En este contexto surgen posiciones en torno al principio de protección del inversor distinguiéndose entre

\footnotetext{
${ }^{1}$ Sobre las conexiones entre la transparencia informativa y el principio de protección del inversor y la eficiencia de los mercados, vid., GARCÍA DE ENTERRÍA, J., «Sobre la eficiencia del mercado de capitales. Una aproximación al Securities Law de los Estados Unidos», en AA.VV., Estudios de Derecho Bancario y Bursátil. Homenaje a Evelio Verdera y Tuells, II, Madrid, 1994, págs. 979-996, pág. 982.
} 


\section{REVISTA VIRTUAL VIA INVENIENDI ET IUDICAND\|}

"CAMINO DEL HALLAZGO Y DEL JUICIO"

http://viei.usta.edu.co/ E-MAIL: revistainveniendi@usantotomas.edu.co

aquella que considera que el inversor es el destinatario primordial de la protección

vía información (denominada por algunos «análisis macroeconómico de la

protección del inversor») y aquella otra que entronca con una perspectiva

institucional según la cual la protección del inversor representa un medio o

instrumento para la protección de los mercados siendo ésta la finalidad prioritaria

de las normas sobre la información («análisis macroeconómico de la protección

del inversor») ${ }^{2}$. Se trata de una concepción funcional o institucional del Derecho

del Mercado de Valores que se enfrenta con aquellas posiciones más

individualistas propias de tiempos pasados en los que la legislación se centraba en

la protección del inversor en su condición de accionista y, en consecuencia, se

realizaba a través de mecanismos propios del Derecho de sociedades que no

resultaron adecuados para garantizar la debida protección del inversor y los

mercados tanto por sus fines como por su alcance ${ }^{3}$.

Por otro lado, además de los deberes y obligaciones de información, el legislador ha adoptado conjuntamente otras medidas para proteger a inversores y mercados. Se tratan de medidas de naturaleza estructural como las relativas a la

\footnotetext{
${ }^{2}$ HORST, P. M., Kapitalanlegerschutz, Haftung bei Emmisión und Vetriebs von Kapitalanlagen. Eine juristische und ökonomische Analyse, München, 1987, págs. 204 y ss. y ASSMANN, H. D., «La responsabilità da prospetto. Tra normativa azionaria e disciplina dei mercati mobiliari», en AA.VV., Il diritto delle società per azioni: problemi, esperienze, progetti, (Dir. Abbadessa, P., y Rojo, A.,), Milán, 1993, págs. 639-683, pág. 656. Este autor alude a los cambios que ha experimentado la concepción del principio de protección del inversor al abandonarse la tradicional concepción individualista que regía la protección del inversor por la protección funcional o institucional, a través de la cual se pretende garantizar la capacidad de funcionamiento del mercado. También se refiere a la Funktionschutz frente a la Individualschutz, HOPT, K., Aktuelle kapitalmarktrechtliche Probleme in der Schweiz, Wirtschaft und Recht, FET 1/1986, págs. 116-129, págs. 125 y ss.

${ }^{3}$ La perspectiva institucional es la que, entendemos, se refleja en las palabras de Martínez Noval, Diario de sesiones del Congreso de los Diputados, núms. 304 y 306 págs. 10269 y 10355, sesiones 14 y 15 de junio de 1988, respectivamente, recogidas por GRACIA RUBIO DE CASAS, M., «Artículo 19. Neutralidad de la inscripción», en AA.VV., Régimen jurídico de las emisiones y ofertas públicas de venta (OPVs) de valores. Comentario sistemático del Real Decreto 291/1992, Dir. Sánchez Calero, F., Madrid, 1995, págs. 429-460, págs. 432 y 433, al señalar «...el objeto de la ley no es la protección del inversor...esta protección es (su) consecuencia...» (Sr. Martínez Noval, Diario de sesiones del Congreso de los Diputados, n. 304 p. 10269, Sesión del 14 de junio de 1988), reafirmando con afortunada retórica, los efectos tuitivos de la difusión de información: «...(nos preguntamos) qué mecanismo....garantizaría la protección del inversor...hemos llegado al convencimiento, por el momento, de que el único mecanismo es justamente ese de que las sociedades emisoras están obligadas a enviar a todos los inversores el folleto informativo...no vemos...otro procedimiento para hacer llegar esa información a...la viuda inversora modesta, que no tiene acceso a los medios de comunicación financieros, que no tiene acceso a informaciones detalladas respecto al contenido de las emisiones a las que acude...estamos protegiendo a inversor que de buena fe invierte sus pequeños ahorros en obligaciones... de manera que nuestra intención es que esas personas puedan tener en sus casas....toda la información que es precisa para juzgar sobre la conveniencia o inconveniencia de suscribir o no una emisión de valores». (Sr. Martínez Noval, Diario de Sesiones no. 306, p. 10355, sesión de 15 de junio de 1988)».
} 


\section{REVISTA VIRTUAL VIA INVENIENDI ET IUDICANDI \\ "CAMINO DEL HALLAZGO Y DEL JUICIO"}

http://viei.usta.edu.co/ E-MAIL: revistainveniendi@usantotomas.edu.co

liquidez de emisores e intermediarios. Estas medidas se complementan entre sí puesto que ambas son necesarias para establecer un marco de confianza y seguridad que permita la liquidez y eficiencia de los mercados. Así, la doctrina distingue entre las «regulaciones de comportamientos», dentro de las cuales se situarían, entre otras, las normas sobre el folleto informativo, y las «regulaciones de estructura», como las que se centran en garantizar la solvencia y liquidez de los emisores y otros participantes en los mercados que, aun siendo de índole diferente, comparten la finalidad de alcanzar mercados más eficientes ${ }^{4}$. En este sentido se ha señalado que las regulaciones de comportamiento «trascienden claramente el plano de la conducta, proyectando sus efectos sobre la estructura misma del mercado: porque al generar confianza, fomentan el acercamiento al mismo de un mayor número de inversores, facilitan la incorporación de empresas a Bolsa, evitan que a la primera bajada de las cotizaciones todos se apresuren a vender, mejorando, en consecuencia, la concentración de operaciones sobre el mercado, la frecuencia y la liquidez de la contratación y confirmando, en definitiva, el dicho popular de que «la honradez es un buen negocio»» ${ }^{5}$.

Por último cabría señalar que la implementación del sistema de transparencia informativa, si bien es un elemento indispensable para la eficiencia de los mercados, puede no ser suficiente para alcanzar niveles adecuados de protección de los intereses del inversor en la medida en que debería de ir acompañado de un aparato sancionador que aporte eficacia al sistema. Se trataría de arbitrar regímenes de responsabilidad anudados al incumplimiento de los deberes de información impuestos a emisores de valores tanto desde un punto de vista sancionador en sentido estricto como reparador del daño, es decir, previendo

\footnotetext{
4 SÁNCHEZ ANDRÉS, A., «La nueva legislación del mercado de valores (Fundamentos económicos y jurídicos para la regulación de la materia)», en Perspectivas actuales del Derecho Mercantil, (Coor. SÁNCHEZ CALERO, F.), Pamplona, 1995, págs. 91-119, pág. 113 y SALINAS ADELANTADO, C., «Desregulación y neoregulación en el mercado de valores», RDM, $\mathrm{n}^{\circ} 224$ abril-junio, 1997, págs. 709-773, pág. 752, cuando se refiere a las las normas relativas a la solvencia y estatuto legal de los participantes en el mercado como normas de protección del mercado.

${ }^{5}$ SÁNCHEZ ANDRÉS, A., «La nueva legislación...», cit., pág. 113.
} 
sistemas de responsabilidad administrativa y penal pero también de naturaleza civil.

En este sentido, la responsabilidad civil, debido a su función reparadora del daño, permite situar al perjudicado, en este caso inversor, en la situación anterior al perjuicio sufrido concurriendo tanto una función reparadora o indemnizatoria como también preventiva de futuras infracciones. Como ejemplo, sirva mencionar el régimen de responsabilidad civil por el folleto de ofertas públicas cuando resulte falso o inexacto, que se ha regulado en distintos ordenamientos y que también se recoge en el Derecho español desde la entrada en vigor del Real Decreto Ley 5/2005, de 11 de marzo, por el que se modifica la LMV.

\section{EL PRINCIPIO DE TRANSPARENCIA INFORMATIVA COMO MECANISMO}

\section{DE PROTECCIÓN DEL INVERSOR.}

El principio de transparencia informativa encuentra sus orígenes en el modelo de las Securites Act de los EE. UU. o modelo del full disclosure, y supone la imposición de un sistema de carga informativa o conjunto de obligaciones de información tanto en el ámbito de los mercados primarios como en los secundarios de valores. Dentro de los mercados secundarios o de negociación derivativa de valores, destaca la información pública periódica «continous disclosure» que el emisor de valores debe ofrecer al mercado de manera periódica así como la información puntual sobre hechos o circunstancias que puedan resultar de interés para el inversor, principalmente porque puedan afectar al precio de los valores, como la regulada en el artículo 82 LMV sobre hechos relevantes ${ }^{6}$. Se trata de evitar situaciones de abuso de la información _insider trading_ por lo que se entiende que la información sensible debe verterse a los mercados lo antes posible para que así se traduzca en los precios consiguiendo un modelo de

\footnotetext{
${ }^{6}$ Vid., entre otros, LARRÁN JORGE, M., Requerimientos informativos de las empresas cotizadas, Madrid, 2003, FERNÁNDEZ PÉREZ, N., La protección jurídica del accionista inversor, Pamplona, 2000, págs. 267 y ss y SÁNCHEZ ANDRÉS, A., «Razones y problemas de la reforma proyectada de la Ley del Mercado de Valores», RDBB, 62, abril-junio, 1996, págs. 357-373, pág. 373.
} 


\section{REVISTA VIRTUAL VIA INVENIENDI ET IUDICANDI \\ "CAMINO DEL HALLAZGO Y DEL JUICIO"}

http://viei.usta.edu.co/ E-MAIL: revistainveniendi@usantotomas.edu.co

eficiencia a este respecto. En cuanto al mercado primario u originario de los valores, como en el caso de ofertas públicas de suscripción o venta de valores, la transparencia informativa se manifiesta en institutos informativos como el folleto.

Tanto si se trata de información referente al mercado primario como al secundario la información exigida comparte unas notas características. Se trata de información obligatoria, que debe cumplir unos parámetros de claridad, veracidad y carácter completo y, por otro lado, es una información controlada por el órgano supervisor de los mercados de valores, en España, la CNMV. En consecuencia, la información es accesible para el público inversor y además debe presentarse conforme a unas reglas y formatos exigidos por la normativa al efecto en aras de una homogeneización de la misma que facilite su comprensión y comparabilidad por expertos e inversores ${ }^{7}$.

El modelo de transparencia informativa basado en una información obligatoria, supervisada y pública, es el mecanismo que el legislador ha establecido para corregir las situaciones de desigualdad o asimetría informativa (en palabras de la doctrina «cadena de desequilibrios informativos»), o al menos aminorar los efectos negativos que esta desigualdad informativa puede desarrollar ${ }^{8}$

El carácter obligatorio de la información se justificaría por la posición de inferioridad del inversor frente a otros sujetos como el emisor de los valores o los

\footnotetext{
${ }^{7}$ Vid. Informe de la Comisión Especial para el fomento de la transparencia y seguridad en los mercados y en las sociedades cotizadas, elaborado por la Comisión Aldama, en cuyo punto II.1 se aludía a que la transparencia implica que se transmite toda la información relevante para los inversores; que es correcta y veraz; se transmite de forma equitativa y es actual. Asimismo, MALARET I GARCÍA, E., «La Comisión Nacional del Mercado de Valores. Una aproximación a su configuración institucional», en AA.VV., Estudios de Derecho Bancario y Bursátil, Homenaje a Evelio Verdera y Tuells, T. II, Madrid, 1994, págs. 1591-1632, pág. 1604.

${ }^{8}$ SÁNCHEZ ANDRÉS, A., La nueva legislación del Mercado de Valores (Fundamentos económicos y jurídicos para la regulación de la materia), Pamplona, 1995, págs. 91-119, pág. 112. Asimismo sobre los problemas de asimetría informativa y los problemas de confianza de los inversores, JIMÉNEZ-BLANCO, D., «La confianza de los inversores: elementos determinantes, Mercados financieros. Nuevas experiencias», Revista Colegio de Economistas, 101, 2004, págs. 18-28, que se refiere, en especial, al carácter de outsider del accionista pequeño, externo, "simple proveedor de capital", frente a otros sujetos (como ciertos accionistas de referencia) que sí pueden ser considerados como insiders, y BLANCO, F., «Asimetrías en la comunicación con los inversores, Mercados financieros. Nuevas experiencias», Revista Colegio de Economistas, 101, 2004, págs. 28-39.
} 


\section{REVISTA VIRTUAL VIA INVENIENDI ET IUDICANDI \\ "CAMINO DEL HALLAZGO Y DEL JUICIO"}

http://viei.usta.edu.co/ E-MAIL: revistainveniendi@usantotomas.edu.co

intermediarios. Desde un punto de vista económico, porque se generarían unos costes excesivos para el inversor y los riesgos de fracaso de la «auto información» del inversor serían muy altos al no tener a su alcance los medios adecuados. En definitiva, un modelo informativo que descansara en la voluntariedad no garantizaría la fiabilidad de la información en detrimento de la seguridad y confianza del inversor ${ }^{9}$.

Cabe concluir en este punto con las acertadas consideraciones contenidas en la Exposición de Motivos del Código de Mercado de Valores portugués cuando señala lo siguiente: «Se trata, del principio del full dislosure, consagrado en la legislación americana desde 1933, y que la CEE, a través de un conjunto ya numeroso de directivas aprobadas o en estudio, procuran implantar en todos los países que la integran. Es evidente que la ley no puede ni debe pretender que el mercado funcione como un «tutor» del inversor, sea cual sea su nivel de cultura y conocimiento en materia de valores mobiliarios; pero puede y debe asegurarle la información necesaria para habilitar al inversor unos conocimientos para tomar por sí mismo una decisión correcta».

\section{TIPOLOGÍA DE INVERSORES EN DERECHO ESPAÑOL}

El artículo 39 RD 1310/2005, recoge una tipología de inversores conforme a la cual pueden distinguirse fundamentalmente entre:

a) Inversor pequeño o no profesional, también conocido como «público no especializado» 0 «average investor» en la terminología anglosajona ${ }^{10}$.

b) Inversor cualificado («Accredited or sophisticated investor»). Concepto acuñado en la Directiva 2003/71/CE, en el que se integran diferentes tipos de inversores como las anteriores categorías de inversores

\footnotetext{
${ }^{9}$ Vid., ASSMANN, H. D., «La responsabilità...», cit., pág. 657.

${ }^{10}$ Se ha afirmado que la delimitación del inversor medio se ha hecho contraponiéndolo a las anteriores categorías de inversor profesional e institucional. En este sentido, TAPIA HERMIDA, A. J., «Los accionistas y el Gobierno de las sociedades cotizadas. Observaciones a la vista de algunas crisis financieras recientes», en AA.VV. Estudios jurídicos en Homenaje al Profesor Aurelio Menéndez, T. II, Sociedades Mercantiles, Madrid, 1996, págs. 2543-2563, pág. 2548.
} 
institucionales, profesionales y también las personas físicas a las que se presupone conocimientos sobre cuestiones financieras.

En concreto, el artículo 39 RD 1310/2005 señala que: «Inversores cualificados y registro de inversores cualificados. 1. A los efectos de lo dispuesto en el artículo 30 bis.1.a) de la Ley 24/1988, de 28 de julio, se considerarán inversores cualificados a las siguientes personas o entidades:

a) Personas jurídicas autorizadas o reguladas para operar en los mercados financieros, incluyendo: entidades de crédito, empresas de servicios de inversión, otras entidades financieras autorizadas o reguladas, compañías de seguros, instituciones de inversión colectiva y sus sociedades gestoras, fondos de pensiones y sus sociedades gestoras, intermediarios autorizados de derivados de materias primas, así como entidades no autorizadas o reguladas cuya única actividad sea invertir en valores.

b) Gobiernos nacionales y regionales, bancos centrales, organismos internacionales y supranacionales como el Fondo Monetario Internacional, el Banco Central Europeo, el Banco Europeo de Inversiones y otras organizaciones internacionales similares.

c) Otras personas jurídicas que no sean pequeñas y medianas empresas.

d) Personas físicas residentes en el Estado español que expresamente hayan solicitado ser consideradas como inversor cualificado y que cumplan al menos dos de las tres condiciones siguientes: $1 .{ }^{a}$ Que el inversor haya realizado operaciones de volumen significativo en los mercados de valores con una frecuencia media de al menos 10 por trimestre durante los cuatro trimestres anteriores. 2. ${ }^{a}$ Que el volumen de la cartera de valores del inversor sea superior a 500.000 euros. 3. ${ }^{\text {a }}$ Que el inversor trabaje o haya trabajado por lo menos durante un año en el sector financiero desempeñando una función que exija conocimientos relativos a la inversión en valores. 
e) Pequeñas y medianas empresas que tengan su domicilio social en el Estado español y que expresamente hayan solicitado ser consideradas como inversor cualificado (...)».

La importancia de distinguir entre estas modalidades de inversores trasciende al ámbito de lo puramente dogmático ya que existen diferencias de régimen jurídico concretas. Estas diferencias se justifican en el hecho de que la protección que el ordenamiento jurídico ofrece al inversor desde las normas del Derecho del Mercado de Valores no tiene que ser homogénea para todas las modalidades de inversor. Así, existen ciertos inversores que gozan de una capacidad informativa notable que puede proceder de su condición de profesional del sector, de su capacidad económica o de cualquier circunstancia (por ejemplo, entidades públicas), que les sitúe en una posición de acceso a la información relevante sobre la inversión que permita su autoprotección. En definitiva, en estos casos no se produciría un desequilibrio contractual entre el emisor/inversor como cuando éste no tiene la condición de inversor cualificado.

Uno de los preceptos más importantes en los que se plasma el diferente régimen jurídico aplicable al inversor medio y al cualificado, es el artículo 30 bis LMV cuyos antecedentes se encuentran en los artículos 6 y 7 del anterior RD 291/1992, ya derogado, y en el que se recogen las excepciones a la obligación de publicar un folleto informativo con ocasión de una oferta pública de valores.

El artículo 30 bis LMV recoge como excepciones a la obligación de publicar el folleto por no tratarse de ofertas públicas: «a) las dirigidas exclusivamente a inversores cualificados; b) las dirigidas a menos de 100 personas físicas o jurídicas sin incluir a los cualificados; c) las dirigidas a inversores que adquieren valores por un mínimo de $50.000 €$ por inversor para cada oferta separada; d) una oferta cuyo valor nominal unitario sea al menos 50.000 euros; e) ofertas de valores por importe inferior a $2.500 .000 €$, cuyo límite se calculará en un período de 12 meses». 
En definitiva, pues, el legislador considera que es principalmente el inversor medio el destinatario de la protección vía información sin perjuicio de que indirectamente el inversor cualificado también se beneficie de esa información. Sin embargo, la tutela ofrecida a través de mecanismos como la responsabilidad civil derivada del folleto en los casos en que existan falsedades, inexactitudes $u$ omisiones relevantes en el contenido del folleto informativo de ofertas públicas, que es el principal instrumento informativo de estas operaciones, excluiría a los inversores cualificados en la medida que la ley no considera que éstos sean los destinatarios de dicho folleto tal y como se desprende del mencionado artículo 30 bis LMV.

\section{LA RESPONSABILIDAD CIVIL COMO MECANISMO DE PROTECCIÓN DEL}

\section{INVERSOR}

En el ordenamiento español existen distintas medidas para la protección del inversor. Cabe destacar, entre otras, el Real Decreto 629/1993, de 3 de mayo, sobre normas de actuación en los mercados de valores, la Orden de 7 de octubre de 1999, que lo desarrolla, la_Circular 3/1993, de la CNMV, sobre registros de operaciones y archivo de justificantes de órdenes, la Orden de 25 de octubre de 1995, de desarrollo parcial del RD 629/1993, de 3 de mayo, sobre normas de actuación en los mercados de valores y registros obligatorios, la Circular 1/1996, de 27 de marzo, de la CNMV, sobre normas de actuación, transparencia e identificación de los clientes en las operaciones del Mercado de Valores, la Circular 2/2000, de 30 de mayo, de la CNMV, sobre modelos normalizados de contrato-tipo de gestión discrecional e individualizada de carteras de inversión y otros desarrollos de la Orden ministerial de 7 de octubre de 1999 de desarrollo del código general de conducta y normas de actuación en la gestión de carteras de inversión o el Real Decreto 1333/2005, de 11 de noviembre, por el que se 
desarrolla la Ley 24/1988, de 28 de julio, del Mercado de Valores, en materia de abuso de mercado.

A pesar de la importancia de estas normas que tienden a procurar al inversor una información más completa sobre las inversiones, los intermediarios y los emisores de valores, en general no recogen regímenes de responsabilidad civil anudados al incumplimiento de los deberes y obligaciones que contemplan.

Por ello, a continuación nos referiremos a uno de los pocos supuestos en los que el legislador sí ha contemplado de manera específica un régimen de responsabilidad civil aplicable a determinados sujetos obligados a suministrar determinada información al inversor. En concreto, se trata del régimen de responsabilidad civil derivada de las inexactitudes y omisiones por el contenido del folleto informativo en ofertas públicas de valores ${ }^{11}$ de la que se ha afirmado que «en algunos segmentos del mercado financiero representa uno de los instrumentos centrales de garantía de una eficaz protección del inversor» ${ }^{12}$.

El folleto informativo es un documento con el contenido determinado por la normativa al efecto, que se presenta bajo unos modelos regulados, registrado en la CNMV y supervisado por esta entidad y editado por el emisor/oferente para su puesta a disposición a favor de los inversores. El artículo 16 del RD 1310/2005 afirma que el folleto «contendrá toda la información que, según la naturaleza específica del emisor y de los valores, sea necesaria para que los inversores

\footnotetext{
11 Vid., sobre esta cuestión, los trabajos monográficos de GRIMALDOS GARCíA, M. I., Responsabilidad civil derivada del folleto de emisión de valores negociables, Valencia, 2001, LÓPEZ MARTÍNEZ, M., La responsabilidad por el contenido del folleto informativo en las ofertas públicas de valores, Madrid, 2003 y VALMAÑA OCHAÍTA, M., La responsabilidad civil derivada del folleto informativo en las ofertas públicas de suscripción y venta de valores, La Ley-Wolters Kluwer, Madrid, 2006. Asimismo, de entre la literatura española sobre esta materia destacan algunos de los primeros trabajos sobre folleto y responsabilidad civil derivada de su contenido como el de FERNÁNDEZ DE ARAOZ , A., La responsabilidad civil de las entidades colocadoras de valores por el contenido del folleto informativo, Madrid, 1995; la obra colectiva dirigida por el Profesor SÁNCHEZ CALERO, F., Régimen jurídico de las emisiones y ofertas públicas de venta (OPVs) de valores. Comentario sistemático del Real Decreto 291/1992, Madrid, 1995 y, en concreto, el trabajo que abordaba el tema de la responsabilidad derivada del folleto de ALONSO UREBA, A., «Artículo 20 y 21. Edición y efectos del folleto», en AA. VV., Régimen jurídico..., cit, págs. 461-498, en especial 489 y ss., y el de SÁNCHEZ-CALERO GUILARTE, J., «Artículos 28 y 29», en AA. VV., Régimen jurídico, cit., págs. 773 y ss.

${ }_{12}$ ASSMANN, H. D., «La responsabilità da prospetto... », en AA.VV., /l diritto delle società..., cit., , pág. 654.
} 
puedan hacer una evaluación, con la suficiente información, de los activos y pasivos, la situación financiera, los beneficios y las pérdidas, así como de las perspectivas del emisor y eventualmente del garante y de los derechos inherentes a tales valores». Es exigido para la realización de diversas operaciones del mercado de valores como en las ofertas públicas de venta y de suscripción, en las OPAS, el folleto de admisión a cotización, o en el caso del folleto de Instituciones de Inversión Colectiva.

El Real Decreto Ley 5/2005, de 11 de marzo, de reformas urgentes para el impulso a la productividad y para la mejora de la contratación pública, modificó en otras normas, la Ley del Mercado de Valores. Diversas fueron las modificaciones introducidas en esta ley por dicha norma y, una de las más importantes, la incluida en el artículo 28 LMV sobre la «responsabilidad por el folleto».

Este precepto fue el primero en recoger por primera vez en Derecho español una referencia a la responsabilidad civil derivada de las falsedades e inexactitudes en el contenido del folleto informativo con ocasión de una oferta pública de valores. Posteriormente, y mediante el RD 1310/2005, se desarrolla el régimen de responsabilidad civil por el folleto (concretamente en los artículos 3237 RD 1310/2005).

Según los artículos 28 LMV y los artículos 32 y ss. del RD 1310/2005, son responsables por el contenido del folleto frente al inversor: el emisor, el oferente (en caso de oferta pública), «la persona que solicite la admisión», si hay solicitud de admisión a cotización, «los administradores de los anteriores», «la entidad directora» ${ }^{13} \mathrm{y}$ «el garante, en su caso». Pero además de estos sujetos, añade el

\footnotetext{
${ }^{13}$ Artículo 35. Responsabilidad de la entidad directora. 1. A los efectos de este artículo, tendrán la consideración de entidad directora aquella, o aquellas, a las que el emisor o el oferente haya otorgado mandato para dirigir las operaciones relativas al diseño de las condiciones financieras, temporales y comerciales de la oferta o admisión, así como para la coordinación de las relaciones con las autoridades de supervisión, con los operadores de los mercados, con los potenciales inversores y con las restantes entidades colocadoras y aseguradoras. 2. La entidad directora resultará responsable cuando no lleve a cabo diligentemente las comprobaciones a las que se refiere este artículo. 3. En el caso de que el emisor u oferente haya otorgado un mandato a una entidad directora para realizar las operaciones a que se refiere el apartado 1, con relación a la primera admisión a negociación de las acciones del emisor que hayan sido previamente objeto de
} 
artículo, serán responsables por el folleto cualesquiera «personas que acepten asumir la responsabilidad por el mismo» y «aquellas no incluidas entre las anteriores que hayan autorizado su contenido».

La responsabilidad de estos sujetos supone la obligación de indemnizar al inversor perjudicado por la adquisición de unos valores negociables sobre la base de un folleto engañoso. En principio, el derecho del inversor sería a obtener la diferencia entre el precio de compra y el precio de los valores en el momento de entablar la acción ${ }^{14}$. Por otra parte, el inversor tendría que probar la relación causa-efecto entre la adquisición de los valores y el daño económico sufrido pero no la culpa del demandado. En este sentido, cabe señalar que el RD 1310/2005 contempla en su artículo 37 un régimen de excepciones a la responsabilidad siempre que pueda probar los extremos recogidos en dicho precepto ${ }^{15}$.

Por último, cabe señalar que la acción para reclamar la responsabilidad prescribe a los 3 años desde que se pudiera conocer la omisión o falsedad.

\begin{abstract}
una oferta pública de venta y el folleto deba ser aprobado por la CNMV, aquella deberá llevar a cabo las comprobaciones que, razonablemente, según criterios de mercado comúnmente aceptados, sean necesarias para contrastar que la información contenida en la nota de los valores relativa a la operación o a los valores no es falsa ni se omiten datos relevantes requeridos por la legislación aplicable. Dichas comprobaciones podrán variar en función de factores como las características de la operación, del emisor y su negocio, de la calidad de la información disponible o facilitada por el emisor o del conocimiento previo que del emisor tenga la entidad directora.
\end{abstract}

${ }^{14}$ Artículo 36. Personas legitimadas para ejercitar la acción de responsabilidad. De conformidad con lo dispuesto en el artículo 28.3 de la Ley 24/1988, de 28 de julio, del Mercado de Valores, las personas responsables por el folleto informativo, de acuerdo con lo dispuesto en los artículos anteriores, estarán obligadas a indemnizar a las personas que hayan adquirido de buena fe los valores a los que se refiere el folleto durante su período de vigencia por los daños y perjuicios que hubiesen ocasionado como consecuencia de cualquier información incluida en el folleto que sea falsa, o por la omisión en el folleto de cualquier dato relevante requerido de conformidad con este Real Decreto, siempre y cuando la información falsa o la omisión de datos relevantes no se haya corregido mediante un suplemento al folleto informativo o se haya difundido al mercado antes de que dichas personas hubiesen adquirido los valores.

\footnotetext{
${ }^{15}$ Artículo 37. Exenciones de responsabilidad. Una persona no será responsable de los daños y perjuicios causados por la falsedad en cualquier información contenida en el folleto, o por una omisión de cualquier dato relevante requerido de conformidad con lo dispuesto en este Real Decreto, si prueba que en el momento en el que el folleto fue publicado actuó con la debida diligencia para asegurarse que: a) La información contenida en el folleto era verdadera. b) Los datos relevantes cuya omisión causó la pérdida fueron correctamente omitidos. No obstante lo anterior, dicha exención no se aplicará cuando dicha persona, con posterioridad a la aprobación del folleto, tuvo conocimiento de la falsedad de la información o de la omisión y no puso los medios necesarios para informar diligentemente a las personas afectadas durante el plazo de vigencia del folleto.
} 
Una vez expuestas, si quiera brevemente, las líneas fundamentales del régimen de responsabilidad civil por el folleto en Derecho español, cabe plantearnos el papel que juega la responsabilidad civil en relación con la protección del inversor.

A este respecto cabe decir, que el hecho de que lo sujetos obligados a suministrar información y, concretamente, a elaborar un folleto completo y veraz puedan resultar responsables por los eventuales vicios del mismo, es un elemento positivo para reforzar la eficacia de la norma que impone el mismo deber del folleto.

La responsabilidad civil cumpliría, en cierta medida, la función de ser la pieza de cierre de un sistema de protección del inversor fundamentado en la información. Otra cuestión es que, partiendo de esta premisa, deban mejorarse algunos aspectos de la regulación contenida en los artículos 28 LMV y 32 y SS. RD 1310/2005, para que la responsabilidad civil cumpla con éxito la función de aportar eficacia ha dicho modelo. En este sentido, algunos aspectos del régimen especial son manifiestamente mejorables en un plano lege ferenda como, entre otros, la delimitación del ámbito de sujetos responsables o el régimen de solidaridad de los mismos. Pero eso es otra faceta de la cuestión cuyo análisis excedería los límites de este trabajo abordar.

\section{CONCLUSIONES}

El inversor necesita protección del ordenamiento jurídico por la asimetría informativa existente en la negociación de valores negociables. Se trata principalmente del inversor medio, no especialista, puesto que el inversor cualificado tiene en principio un mayor acceso informativo.

El Derecho del Mercado de Valores español, al igual que sus homólogos, se asienta sobre los principios de transparencia informativa y eficiencia de los 
mercados. La información no es un fin sino un medio para alcanzar la debida protección de los mercados y, por ende, del inversor. Pero un sistema de información aunque sea obligatorio y desarrollado en su contenido, como el de la mayoría de los países europeos, no es suficiente para garantizar niveles adecuados de protección del inversor si no se acompaña de instrumentos jurídicos que sirvan para persuadir a los obligados a dicha información a cumplir la norma, como en el caso de los emisores de valores. Concretamente, se deben establecer sistemas eficaces de responsabilidad civil que sirvan para reparar los eventuales daños económicos sufridos por un inversor a consecuencia de informaciones engañosas pero que también desarrollen una función preventiva evitando daños futuros derivados del incumplimiento de dichas obligaciones de información. Para ello no sólo es necesario que existan regímenes de responsabilidad civil aplicables sino que éstos sean lo suficientemente completos y específicos para poder resolver los singulares problemas que la inversión en valores negociables plantea.

\section{BIBLIOGRAFÍA}

ALONSO UREBA, A., en AA.VV., Régimen jurídico de las emisiones y ofertas públicas de venta (OPVs) de valores. Comentario sistemático del Real Decreto 291/1992, dir. Sánchez Calero, F., Madrid, 1995, «Artículos 20 y 21. Edición y efectos del folleto» págs. 463-498.

ASSMANN, H. D., «La responsabilità da prospetto. Tra normativa azionaria e disciplina dei mercati mobiliari», en AA.VV., I/ diritto delle società per azioni: problemi, esperienze, progetti, (Dir. Abbadessa, P., y Rojo, A.,), Milán, 1993, págs. $639-683$ 
FERNÁNDEZ PÉREZ, N., La protección jurídica del accionista inversor, Pamplona, 2000.

GARCíA DE ENTERRÍA LORENZO-VELÁZQUEZ, J., «Sobre la eficiencia del mercado de capitales. Una aproximación al Securities Law de los Estados Unidos», en AA.VV., Estudios de Derecho Bancario y Bursátil. Homenaje a Evelio Verdera y Tuells, II, Madrid, 1994, págs. 979-996.

GRACIA RUBIO DE CASAS, M., Artículo 19. Neutralidad de la inscripción, en AA.VV., Régimen jurídico de las emisiones y ofertas públicas de venta (OPVs) de valores. Comentario sistemático del Real Decreto 291/1992, dir. Sánchez Calero, F., Madrid, 1995, págs.429-460.

GRIMALDOS GARCÍA, M. I., Responsabilidad civil derivada del folleto de emisión de valores negociables, Valencia, 2001.

HOPT, K., Aktuelle kapitalmarktrechtliche Probleme in der Schweiz, Wirtschaft und Recht, FET 1/1986, págs. 116-129.

HORST, P. M., Kapitalanlegerschutz, Haftung bei Emmisión und Vetriebs von Kapitalanlagen. Eine juristische und ökonomische Analyse, München, 1987.

LARRÁN JORGE, M., Requerimientos informativos de las empresas cotizadas, Madrid, 2003.

LÓPEZ MARTÍNEZ, M., La responsabilidad por el contenido del folleto informativo en las ofertas públicas de valores, Madrid, 2003. 
MALARET I GARCÍA, E., «La Comisión Nacional del Mercado de Valores. Una aproximación a su configuración institucional», en AA.VV., Estudios de Derecho Bancario y Bursátil, Homenaje a Evelio Verdera y Tuells, T. II, Madrid, 1994, págs. 1591-1632 y en REDA, 76, 1992, págs. 557-597.

SALINAS ADELANTADO, C., «Desregulación y neoregulación en el mercado de valores», RDM, n²24, abril-junio, 1997, págs. 709-773.

SÁNCHEZ ANDRÉS, A., «La nueva legislación del mercado de valores (Fundamentos económicos y jurídicos para la regulación de la materia», en Perspectivas actuales del Derecho Mercantil, (Coor. SÁNCHEZ CALERO, F.), Pamplona, 1995, págs. 91-119.

- «Razones y problemas de la reforma proyectada de la Ley del Mercado de Valores», RDBB, 62, abril-junio, 1996, págs. 357-373.

SANCHEZ-CALERO GUILARTE, J., en AA.VV, Régimen jurídico de las emisiones y ofertas públicas de venta (OPVs) de valores. Comentario sistemático del Real Decreto 291/1992, Dir. Sánchez Calero, F., Madrid, 1995, «Artículo 8. Normas generales y Artículo 29. Requisitos exigibles», págs. 213 y ss. y 803-831, respectivamente.

TAPIA HERMIDA, A. J., «Los accionistas y el Gobierno de las sociedades cotizadas. Observaciones a la vista de algunas crisis financieras recientes», en AA.VV.; Estudios jurídicos en Homenaje al Profesor Aurelio Menéndez, T. II, Sociedades Mercantiles, Madrid, 1996, págs. 2543-2563. 
REVISTA VIRTUAL VIA INVENIENDI ET IUDICANDI

"CAMINO DEL HALLAZGO Y DEL JUICIO"

http://viei.usta.edu.co/ E-MAIL: revistainveniendi@usantotomas.edu.co

VALMAÑA OCHAÍTA, M., La responsabilidad civil derivada del folleto informativo en las ofertas públicas de suscripción y venta de valores, La Ley-Wolters Kluwer, Madrid, 2006. 